\title{
Exploring the Conceptual Understanding of the Quadratic Function Concept in Teachers' Colleges in Zimbabwe
}

\author{
Lillias Hamufari Natsai Mutambara ${ }^{{ }^{*}}$, Jane Tendere ${ }^{2}$, Conilius Jaison Chagwiza ${ }^{1}$ \\ ${ }^{1}$ Bindura University of Science Education, ZIMBABWE \\ ${ }^{2}$ Mutare Teachers College, ZIMBABWE
}

Received 20 June 2019 - Revised 25 September 2019 - Accepted 25 September 2019

\begin{abstract}
This paper reports on an exploration of preservice teachers' understanding of the quadratic function concept in Zimbabwe. These concepts were taught to preservice teachers studying for a diploma in Education wishing to specialize in the teaching of Ordinary level mathematics. Concerns about high Mathematics failure rate in Zimbabwean Secondary Schools have prompted this investigation into finding out if teachers' understanding of quadratic function concept could be the cause. The study adopted the APOS (action-process-object-schema) to investigate their conceptual understanding of the concepts. Data were generated from students' responses to a written task and follow up interviews were used to solicit information from the preservice teachers. A designed genetic decomposition for quadratic concepts was used as an analysis tool. The findings of the study also revealed majority of the preservice teachers seemed to be operating at the action level of understanding, with very few teachers who have reached the object level. It was noted that the preliminary genetic decomposition failed to accommodate all students' responses which lead to the development of a modified genetic decomposition.
\end{abstract}

Keywords: APOS theory, genetic decomposition, quadratic function

\section{INTRODUCTION}

The study particularly focuses on function concept because of its relevance in a variety of situations. Functions in general are considered to be some of the most important topics in mathematics (Cooney \& Wilson, 1993; Dreyfus \& Eisenberg, 1984; Romberg, Carpenter, \& Fennema, 1993; Zaslavsky, 1997), cited in Parent 2015. Mathematics is described as the queen and servant of all school subjects, since it cuts across the school curricula (Akpan, 1987; Fajemidagba, 1986). It is generally linked to the development of any nation in the world. It is actually a discipline that almost every sector calls for in the world. In Zimbabwe, both primary and secondary teacher training colleges have ordinary level mathematics as requirement for enrolment to prospective teachers. The focus of tertiary education policy in Zimbabwe is mainly rooted in Science, Technology, Engineering and Mathematics (S.T.E.M). It is noted with great concern that in secondary schools, these subjects are poorly performed. This study will mainly focus on finding out if the quality of teachers produced from teachers' colleges could be the cause of this situation.

Ndlovu and Brijall (2015) purported that many students performed badly in mathematics because their learning is associated with a lack of conceptual understanding of concepts. Learners can display conceptual understanding which can be referred to as an integrated and functional grasp of mathematical ideas. When learners have conceptual understanding they know more than isolated facts and methods. They understand why a mathematical idea is important and even the kinds of contexts in which it is useful. In addition to that, they have their knowledge organised into a coherent whole which will make it possible to learn new ideas by connecting those ideas to what they already know. Conceptual understanding also supports retention of facts. When students have conceptual understanding they can even try to explain a method to themselves and try to correct it if necessary, (Jojo, 2011).

(C) 2020 by the authors; licensee Modestum Ltd., UK. This article is an open access article distributed under the terms and conditions of the Creative Commons Attribution License (http://creativecommons.org/licenses/by/4.0/). $\square$ tendaimutambara@gmail.com (*Correspondence) $\square$ tenderejane@gmail.com $\square$ cchagwiza2@gmail.com 


\section{Contribution of this paper to the literature}

- The study focused on finding out if the quality of teachers produced from teachers colleges is the ones causing high failure rate in mathematics in Zimbabwean Secondary Schools.

- Identification of preservice teachers understanding of quadratic function concepts was described in terms of APOS theory (action, process, object, schema), so as reveal the specific mental construction made.

- The results of this study revealed that the preservice teachers are operating at different conceptual levels of understanding leading to use of different teaching instructional strategies in secondary schools. It is important for teachers to understand concepts clearly before they teach the pupils.

In colleges, lecturers have worked with students from different Mathematical backgrounds, varying from little understanding of Mathematical concepts to more sophisticated ways of thinking of Mathematical concepts. The student teachers under study have their ages ranging from 19 years to 40 years. This implies that some have since left school while others are fresh from school resulting in different levels of understanding concepts. Despite the differences in abilities of students, the one issue that seems to be common to all is that students have an APOS level at which they are operating as they deal with quadratic functions. It was therefore, important for the researcher to investigate on the levels the preservice teachers are operating on quadratic functions before they go for Teaching Practice Attachment (TPA). It is the goal of this study to gain more insight about the ways in which (preservice teachers) or student teachers understand the quadratic function concept at entry point to their course.

Sets, functions and coordinate geometry are one of the first modules offered to first years as they get into college. The researchers decided to investigate on quadratic functions because it is one of the topics entailed in this module and is poorly performed by " $\mathrm{O}$ " level students. From the researchers teaching experiences at secondary school, the topic on quadratic equations are done badly at Ordinary level. Concepts covered include parabolas, vertices, intercepts and vertex form. The researchers happened to have taught this module for several years and discovered that during lectures most students were not comfortable to explain some of these concepts to their colleagues. It was also noted that averagely the students did not perform well on the end of module test implying that they would not have understood the concepts. The researchers has been particularly interested in not only how the student teachers understand quadratic functions, but also why they choose certain strategies and procedures for solving quadratic functions. The researchers' were interested in researching the common misconceptions that students have about quadratic functions and the most effective teaching strategies that will help their pupils understand quadratics much better.

\section{LITERATURE REVIEW}

Parent (2015) views a function as a relation with every element in the domain having a unique image. In this study, functions are narrowed down to quadratic function concept. Mathematical understanding basically exists as procedural knowledge, conceptual knowledge or both. Conceptual understanding involves content mastery where knowledge can be generated and established through many relations between existing and prior knowledge and transferred through reconstruction of procedures (Donevska-Todorova, 2016). Procedural knowledge is chiefly concerned with steps followed as one learns a concept. Jojo (2011) argues that learners with conceptual understanding can easily explain the methods to their colleagues resulting in fact retention and reconstruction when forgotten. Kotsopoulos (2007) cited in Parent (2015) points three forms of the quadratic function which are the standard form, factored form, and the vertex form. Students get confused when quadratic function concepts are presented in different ways which they are not used to. The structure $y=a x^{2}+b x+c$ (where $\mathrm{a} \neq 0$ and $a, \mathrm{~b}$ and $c$ are constants) is the standard form of a quadratic function form revealing the location of the $y$-intercept $(0, c)$. The vertex form: $y=a(x-p)^{2}+p$ clearly highlights the turning point of the parabola (vertex) represented by $\mathrm{V}(p, q)$. Lastly, the factored form: $y=a\left(x-x_{1}\right)\left(x-x_{2}\right)$ indicating the position of the $x$-intercept $\left(x_{1} ; 0\right)$ and $\left(x_{2} ; 0\right)$ (Zaslavsky, 1997; Ellis \& Grinstead, 2008). Kotsopoulos gives the example of $x^{2}+3 x+7=x+4$ being not in standard form and causing students trouble when asked to perform various tasks with it. Graph associated with quadratic functions is called a parabola (Chazan, 1992). In order to effectively discuss the effects of varying constants on the function $y=\left(a x^{2}+b x+c\right)$, Ibeawuchi (2010) noticed that as the value of $a$ got bigger, the thinner (steeper) the graph became. Also, a decrease in the value of $a$, resulted in the graph becoming more shallow. Changing the value of $a$ to a negative, resulted in the parabola being reflected about the $x$-axis. For the same parabola, changing the values of $b$ maintaining the values of $a$ and $c$ unchanged, caused shifts for the range of values changed, however, the parabola remained the same in terms of its shape and direction. Altering value of $c$ resulted in graph shifting along the y axis by $c$ units (up if $c$ is non negative and down if $c$ is negative). The line $x=-\frac{b}{2 a}$ is the axis of symmetry irrespective of the value of c. To obtain the value of $y$ at $x=-\frac{b}{2 a}$ which is the turning point of the parabola, there is need to substitute $x=-\frac{b}{2 a}$ into the equation $y=a x^{2}+b x+c$, (Owens, 
1992). Students who possess procedural knowledge only make a lot of misconceptions (Siyepu, 2013). Misconceptions are wrong ideas which are constanly used (Parent, 2015). Ellis and Grinstead (2008) argued that learners bring to the classroom different understanding about coefficients, $a, b$ and $c$ in the quadratic function, most of them believed the coefficient represented the slope of a quadratic function. Some were not sure whether the coefficients have an effect on the vertex or not. Borgen and Manu (2002) point out that a student who performs well in class may appear to have basic understanding of quadratic function concepts, but in reality, they may not have a conceptual understanding of the concept. This was proved through videotaping two students working together on a problem then comparing their written work and the oral interviews. Misconceptions may be caused by some difficulties which develop as a result of over-generalizing an essential correct conception or interferences from everyday knowledge (Leinhardt et al., 1990, cited in Parent, 2015). Other learners could not separate a function from a non-function. They also failed to use notation within the graph of a function itself. In an effort to understand learners' understanding of concepts some researchers would show participants' written work and interview transcripts reports illustrating how the data was collected (Bourdieu, Chamboredon \& Passeron, 2000). However this study employed APOS theory to describe and analyse pre-service teachers' knowledge construction of the quadratic function. The main aim of applying the APOS theory was to reveal the nature of preservice teachers' mental constructions. To explore the nature of mental constructions, the following research questions were explored:

- How do preservice teachers understand the quadratic function concept?

- How do preservice teachers mental constructs of APOS link with preliminary genetic decomposition?

\section{THEORETICAL FRAMEWORK}

This research is anchored on APOS theory (Dubinsky \& McDonald, 2001). The theory informs and guides data collection and analysis (Maharaji, 2013). The acronym APOS stands for action, processes, object and schema. Dubinsky (1991) initially introduced the major components of the theory as what goes through one's mind when trying to learn a Mathematical concept. In this framework, learners mentally construct their understanding of mathematical concepts. This framework is carried out using the ACE teaching cycle, which is a pedagogical approach consisting of three components repeated in a cycle. The three components are: (A) activities, (C) classroom discussion, and (E) exercises. The initial stage of the cycle involves activities performed outside the class (Asiala et al., 1996). Maharaj (2013) claims that learning is facilitated if the individual possesses mental structures appropriate for a given mathematical concept. If the appropriate mental structures are absent, learning the concept becomes almost impossible to learn. It is therefore important to develop teaching methods that help students develop mathematical understanding. The APOS theory emphasises that conceptual formation works in stages and the construction of a complete mental structure operate through, the mental structures: actions, processes, objects, and schemas. Action is an external change of objects which occurs in stages showing how an operation is performed. It is characterised by specific instructions to be performed (Dubinsky \& Mcdonald, 2001). At an action level of understanding, a learner, when working with the quadratic function concept like the vertex would need the formula $\frac{-b}{2 a}$ in order to locate the vertex then moves on to the process stage. Process refers to a mental construction that is made by an individual when an action is repeated and reflected upon it. When an individual repeats an action, this action may be interiorised into a mental process (Dubinsky \& Mcdonald, 2001). Maharaji (2013) refers to a process as a mental structure occurring wholly in the mind of the individual. A student with a process understanding can think of performing the same kind of action without the need of external stimuli. Dubinsky and Mcdonald (2001) further says that an individual might just think of performing a process without actually doing it. In continuation of the above example, at the process stage an individual can now find the vertex of any quadratic function, without the need of an explicit formula to follow. Object is a structure from a process where the individual becomes aware of the process as a whole and realises that change can act on it. If the learner can appreciate this and can actually build the changes, then it can be said that the learner has encapsulated the process into a cognitive object (Dubinsky \& Mcdonald, 2001). In continuation from the above example, an individual who is able to compare, relate two vertices of a quadratic function, and create linkage between concepts has encapsulated the process into objects, so for that particular concept, the level of understanding was object level. Schema is an organised and linked logical framework of an individual's collection of actions, processes, objects and other related schemas. The linkage is due to the fact that it provides an individual with a way of deciding, when presented with a mathematical problem (Dubinsky \& Mcdonald, 2001). This framework occurs in an individual's mind when faced with a problem situation that involves the concept. At this stage, one can apply the concept in real life situations. The main objective of an APOS analysis is to point to possible pedagogical strategies for helping students learn it. The theoretical analysis proposes the use of a genetic decomposition. 


\section{Genetic Decomposition}

The genetic decomposition is a set of mental constructions that a student might make in order to understand a Mathematical concept being studied (Dubinsky, 2001). This is also supported by (Jojo et al., 2013) who also outlines that a genetic decomposition is the structured set of mental constructs which describe how any given concept can develop in the mind of an individual. The preliminary genetic decomposition of the concept on quadratic equation is guided by the researchers' teaching experiences and how they understand this concept. Figure 1 illustrates the proposed preliminary genetic decomposition of the concept of the quadratic equations according to APOS theory. If the differences in students' performance cannot be explained by the genetic decomposition that would imply that the genetic decomposition needs revision (Ndlovu \& Brijlall, 2015).

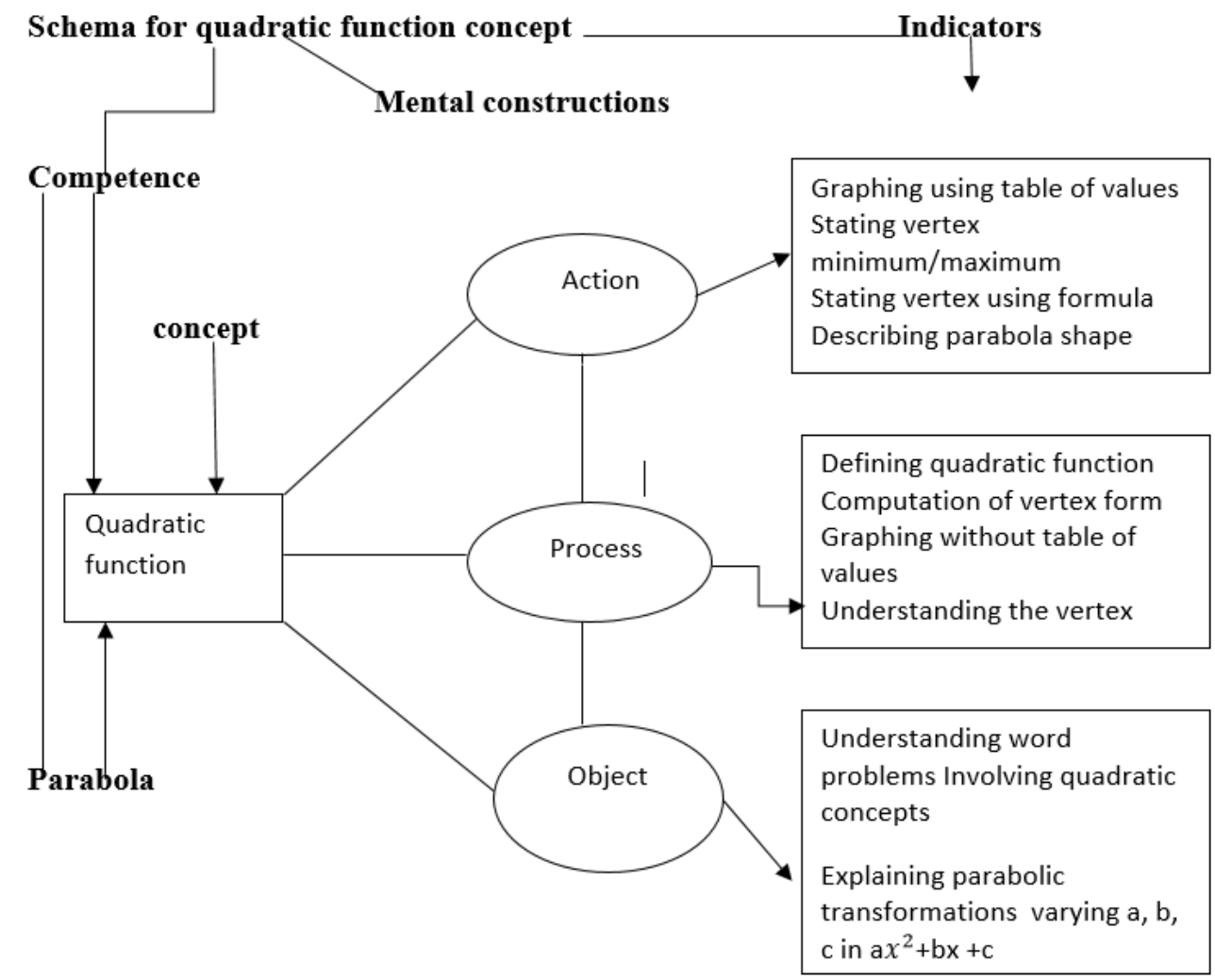

Figure 1. Preliminary genetic decomposition for the concepts of quadratic function according to APOS theory, Adopted from Ndlovu and Brijlall (2015)

\section{METHODOLOGY}

\section{Research Design}

In this study, we used the interpretive research paradigm. This study is qualitative in nature whereby a case study design was employed to explore students' understanding of the quadratic function concepts. Hartley (2004) views a case study as a detailed investigation characterized by collection of data within a long period. A concept is usually analyzed within a specific context. This design was selected because it deals with real life context. Hartley also noted that this design has an advantage as it can be undertaken by one researcher who is intensively active, so it does not require a team of researchers to carry out the research. By its nature, qualitative research methodology allows one to use different research strategies to collect data. It also allows for the voice of the participants to be heard. This study used interviews, document analysis since the study is concerned with exploration of quadratic concepts. The qualitative paradigm allows the researcher to skillfully devise a tool to probe deeply within the minds or attitudes, feelings and reactions of the respondents.

\section{Participants}

This research comprised a group of twenty four preservice teachers taking their first year diploma in education at a teachers' college in Zimbabwe. The students specialised in Mathematics as a double major subject, and all of 
them were post A Level students. These student teachers' conceptual levels of understanding were explored before they go for Teaching Practice Attachment (TPA).

\section{Tasks}

The data were generated through written responses of the twenty four students. Sets, Functions and Coordinate Geometry module is one of the first modules offered to First year Mathematics student teachers at the college. The researchers decided to investigate on quadratic function concept because it is one of the topics entailed in this module. On the other hand, other aspects like maximums, minimums, vertices and graph transformations are part of ' $\mathrm{O}$ ' level syllabus which the student teachers would teach in schools. Concepts covered include parabolas, vertices, intercepts, word problems and vertex form. One of the researchers happened to have taught this module for seven years and discovered that during lectures, most students were not comfortable with explaining some of these concepts to their colleagues. It was also noted that averagely, the students did not perform well at the end of module test implying that they would not have understood the concepts.

\section{Data Collection}

Five tasks on quadratic functions were administered to the students and data was generated through written responses of the twenty four students. Ten students were sampled out to participate in the follow up interviews basing on their performance that is those who performed very well, the average performers and those who did badly. The researcher conducted follow up interviews within 20 to 30 minutes duration. An interview schedule was prepared. The purpose of the interview was explained prior to conducting the interview. The confidentiality of their names and the time needed was also highlighted to them. Fictitious names for the participants have been used to ascertain confidentiality and anonymity. During these interviews, the participants had the chance to clearly explain their written responses. The researcher had to probe them in order to solicit the required information. The interview questions were guided by the students' responses on their answer scripts. Interview conversations were presented as interview excerpts.

\section{Data Analysis}

Written exercises were presented as extracts. Findings from the questionnaires were also presented in the form of tables. Descriptive statistics was used to analyze data from semi-structured interviews and document analysis. Data analysis was mainly based on the preliminary genetic decomposition. In order to test the feasibility of the genetic decomposition, students' written responses to five assessment items were analyzed as part of this exploratory study. The tasks are presented below.

\section{RESULTS}

\section{Understanding of the Definition of Quadratic Function}

Question 1 aimed to explore the preservice teachers understanding of the definition of the concept quadratic function. The question addresses the action and process level of the genetic decomposition. This question is illustrated below.

Table 1. Question 1

1a) Define the term quadratic function

b) Explain how you would introduce this concept to a ZJC class.

Questions $1 \mathrm{a}$ and $1 \mathrm{~b}$ were concerned with definition of a quadratic function. They were treated as item 1 since question $1 \mathrm{~b}$ was just a follow up of question 1a. A variety of definitions came out from the students' written work on question 1a) which required them to define a quadratic function. Table 2 summarises what the twenty-four students wrote as their definitions of functions.

Table 2. Frequencies of scores on item 1

\begin{tabular}{lc}
\hline Definition of a quadratic function given by students & Frequency \\
\hline An equation with two as the highest power of the unknown. & 6 \\
\hline An algebraic expression as two as the highest power of the unknown. & 6 \\
\hline A function as two as the highest power of the unknown. & 11 \\
\hline A relationship between range and domain such that the highest power of the domain is two. & 1 \\
\hline
\end{tabular}


Table 2 shows that all the 24 students could not give an explicity definition of the term but had an idea of the greatest power of the variable being 2. Analysing these results, it is evident that the students lacked a clear understanding of the meaning of the term function because they treated the quadratic function in parts, rather than as a complete unit. Most of them interchanged the word function with words like equation and expression. Some just used the same word to define itself, implying that they were not in a position to explain its meaning. These findings depicted a big gap between Zaslavsky (1997)' proposed function definition and the student teachers' responses. The idea of mapping one input to one output was not known to the student teachers. They just concentrated on the quadratic aspect only. One student thought that all relationships between range and domain can be called functions, yet a function is a special type of a relationship. However, they all remembered or agreed that the highest power of the unknown is two. The results show that on this concept on definition, the students are operating at action level since they had managed to identify the rule to use during their mental constructions (Dubinsky, 1991). In this case, the presence of an unknown in the expression with 2 as its highest power is the rule for defining a quadratic function. Question $1 \mathrm{~b}$ was a follow up of question $1 \mathrm{a}$. The researchers used this question to further probe the students' understanding of the term quadratic function. Their conceptual understanding of the term was to be measured by the way they explained the concept to pupils as indicated by Shulman (1986) when he said that teachers need effective ways of representing the meaning of concepts they would teach. Some written work extracts and some interview excerpts for selected students are shown below.

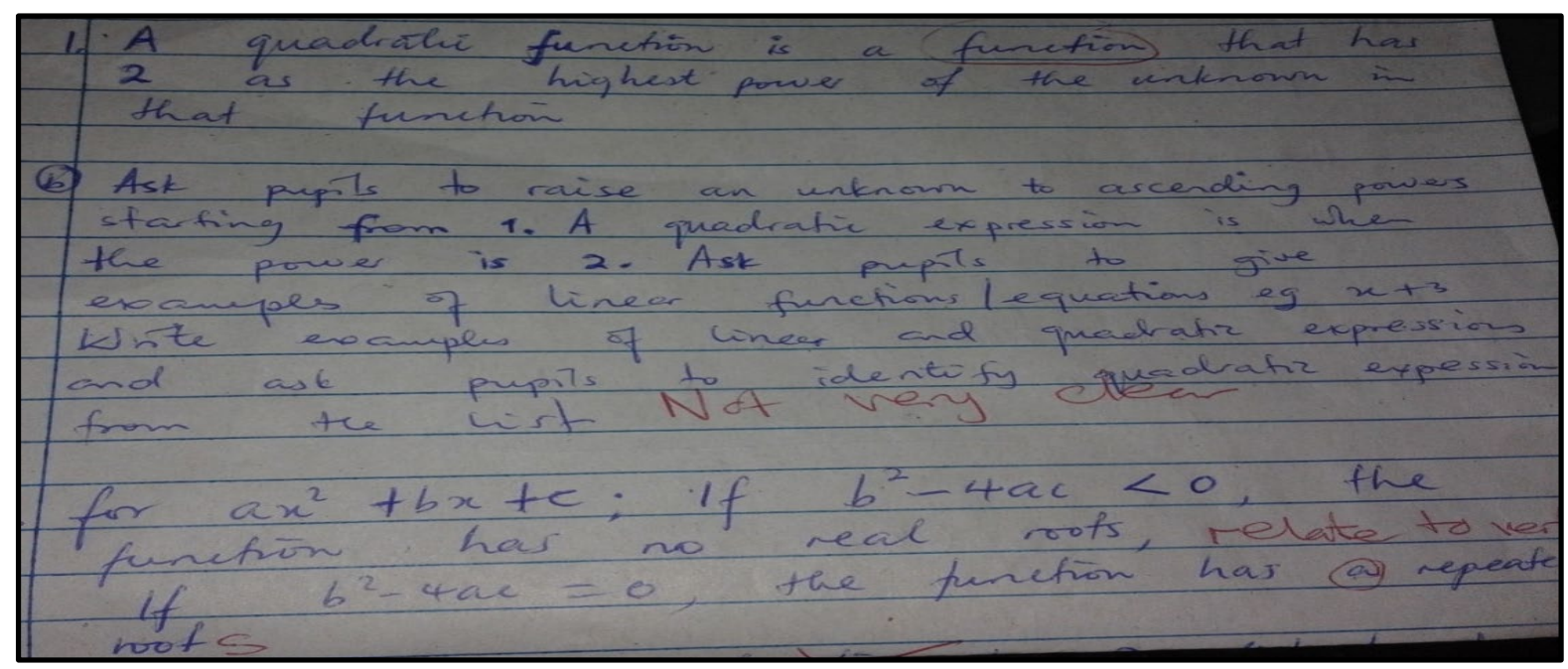

Figure 2. Far's written response on understanding of the quadratic function

Far defined a function as a relationship between domain and range. The quadratic part is the one he defined as being raised to the power two. The student does not realize that a function is made up of three components, which are domain, range and rule of correspondence. An incomplete description of the concept places Far in the action stage of APOS. His response to question $1 \mathrm{~b}$ confirms that he is in the action stage of APOS since the explanation is vague. An interview was carried in order to get some clarification on what he wrote.

\section{Far's Interview Responses (Excerpt 1)}

Interviewer: What do you mean when you say it is the relationship between range and domain?

Far: The terms come from algebraic expression where unknown value is the domain, and then the range is what you get after substitution.

Interviewer: How else can we define a quadratic function?

Far: Yes, it's more of an equation where the $f(x)$ is represented by $y$ axis.

Interviewer: So does it mean that a function is an equation?

Far: Yaa function and equation are equal.

Interviewer: Besides recap of the previous lesson, how would you introduce this concept to pupils?

Far: Teach them how to plot graph from a table of values

From the interview excerpt, it can be deduced that Far fits in the action stage of the APOS stage because he could not make a clear distinction between a function and an equation, and could not explain it in terms of highest exponent of the function being equal to two. The extract below shows Olly's written work. 


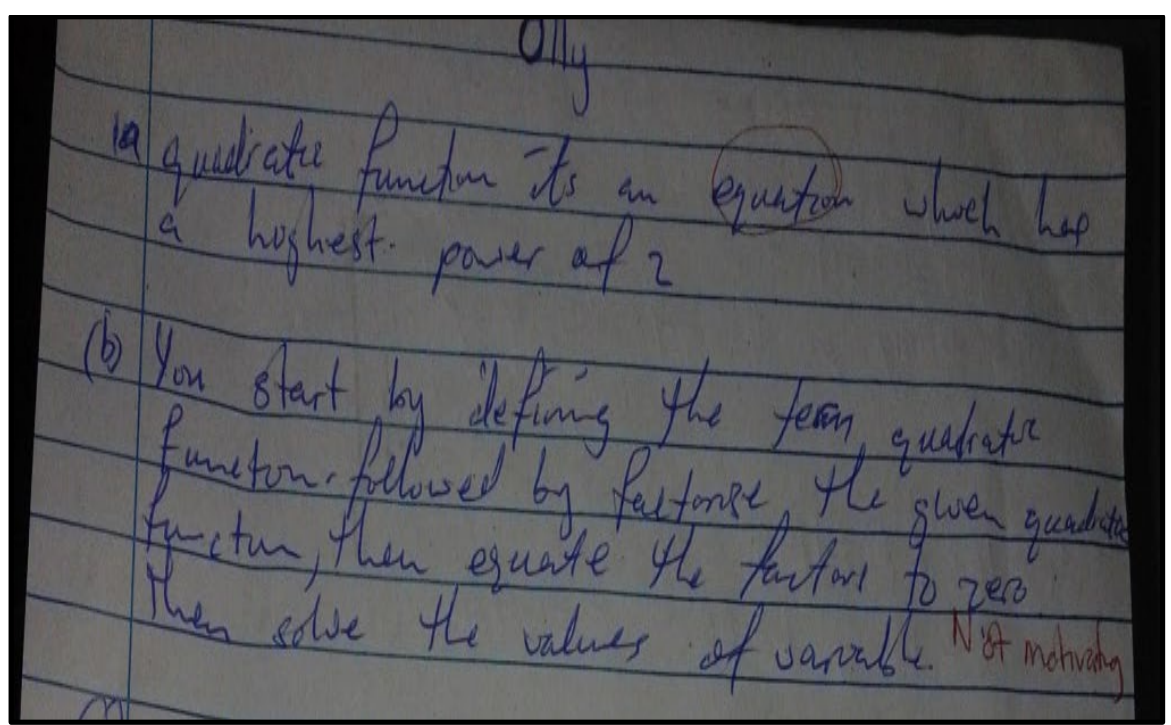

Figure 3. Olly's written response on understanding of quadratic functions

Question 1a required the respondent to define a quadratic function and to explain how it would be introduced to ZJC class. Olly could not define a quadratic function clearly. His response to part $1 \mathrm{~b}$ also indicated that his introduction would be a weak one. Olly's response indicates that he has not reached the action level using the genetic decomposition on Figure 2. He is operating at the pre function level for question 1 (Dubinsky, 2011).

\section{Olly's Interview (Excerpt 2)}

Interviewer: Is a function the same as an equation?

Olly: 1 think they mean the same.

Interviewer: 2 is the highest power of which values in the equation?

Olly: $x$ value.

Interviewer: Do you think this is a motivating introduction to pupils?

Olly: Yes, since it is a new concept, the teacher has to define it for them.

Interviewer: How is the assumed knowledge of linear equations linked to the new concept?

Olly: there is no linkage.

Interviewer: Is the gradient of a quadratic function uniform as that of linear function?

Olly: there is no difference.

From this interview, it was noted that Olly had a vague idea about the quadratic function concept. He was not even prepared to go and deliver the concept confidently to ZJC pupils. The learner lacked knowledge of gradients and linear functions. This interview confirms that Olly is operating at the pre-function level, (Breidenbach, Dubinsky, Hawks, \& Nicholas, 1992).

\section{Transformations on Vertices of Parabolas}

Question 2 aims to explore the preservice teachers understanding of the knowledge transformation on vertices of parabolas. The question addresses the action and process level of understanding according to APOS theory. The question is represented in Table 3 and the frequencies of responses are shown in Table 4.

Table 3. Question 2

Discuss the relation of $\mathrm{a} ; \mathrm{b} ; \mathrm{c}$ in the quadratic function: $a x^{2}+b x+c$ (standard form of a quadratic function). What do these coefficients do the graph vertex?

Table 4. Frequencies of Responses on item 2

\begin{tabular}{cccccc}
\hline Category & $\mathbf{1}$ & $\mathbf{2}$ & $\mathbf{3}$ & $\mathbf{4}$ & $\mathbf{5}$ \\
\hline \multirow{2}{*}{ Indicator } & $\begin{array}{c}\text { Not answered } \\
\text { /incorrect answers }\end{array}$ & $\begin{array}{c}\text { Only described } \boldsymbol{a} \\
\text { and } c \text { only }\end{array}$ & $\begin{array}{c}\text { Explained how } a \\
\text { affects the vertex }\end{array}$ & $\begin{array}{c}\text { Effect of } a \text { and } c \text { on } \\
\text { vertex }\end{array}$ & $\begin{array}{c}\text { All correctly } \\
\text { answered }\end{array}$ \\
\hline Number of responses & 7 & 5 & 9 & 2 & 1 \\
\hline
\end{tabular}

The question required the learner to describe transformations on vertex of parabola after changing values of $a, b$, and $c$ on the quadratic function in the form $a x^{2}+b x+c$, where $a \neq 0, \mathrm{a}, \mathrm{b}$ and c are constants. We noted that only one student was able to give a completely correct response and seven did not answer the question or have incorrect responses. Most candidates were familiar with the effects of varying $a$ and $c$ only. However, most students 
focused on changes which occur when the value of $a$ takes positive and negative values. These findings were similar to Chazan (1992)'s who indicated that as the value of a gets bigger, the parabola becomes steeper and as the value of a gets smaller, the fatter the graph. From Chazan's work, it is clear that use of diagrams could have facilitated the explanations of the transformations on these parabolas. However, the concept of increasing or decreasing the $a$ value was not discussed by many students. For $b$ most students had no idea on its effect on the vertex of the parabola. Students' written work and interview excerpts were highlighted below.

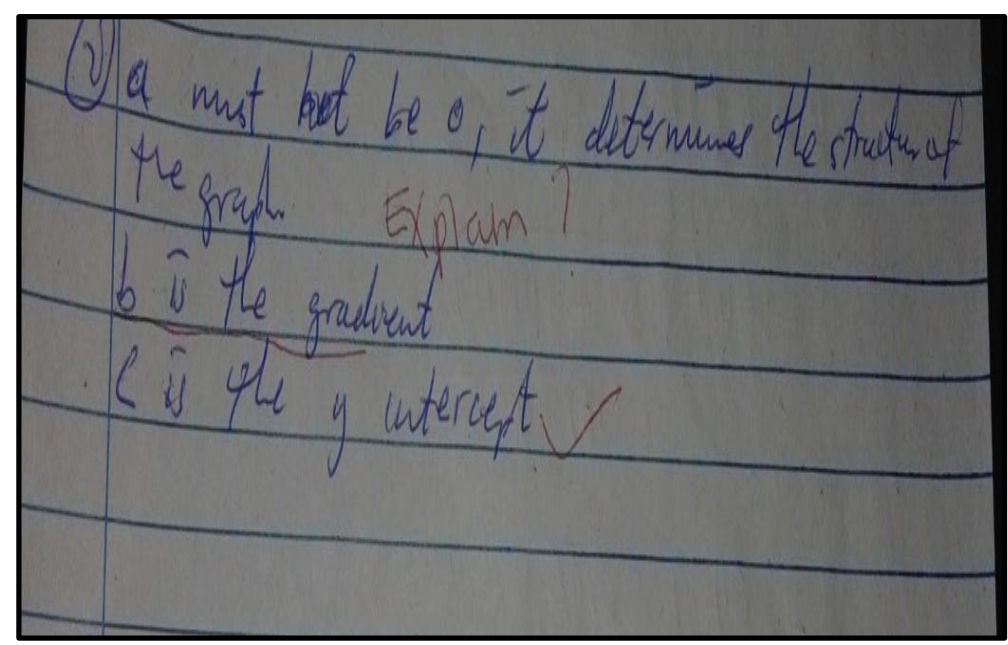

Figure 4. Olly's written response on transformation on vertex of parabola

The question required the candidates to be familiar with the standard form of a quadratic function $a x^{2}+b x+$ $c$, explaining the effects of varying the constants $a, b, c$ to the graph vertex. Olly could not link the constants with the parabola. The student teacher failed to come up with actions, rules or procedures to form an action on solving the problem. The student teacher is operating at this level which is below action level but the preliminary genetic decomposition on Figure 2 failed to allocate a level for Olly. To confirm this, the researcher carried out an interview and the excerpts are shown below.

\section{Olly's Interview (Excerpt 3)}

Interviewer: Could you explain the effects of varying the constants; $a, b, c$ on the vertex of a parabola?

Olly: What 1 remember is that " $a$ " should never be zero for one to be able to draw the graph.

Interviewer: How about $b$ and $c$ ?

Olly: $b$ is the gradient of the graph and $c$ is the y intercept.

Interviewer: Is the gradient of a parabola uniform?

Olly: It is the same as the gradient of a linear function.

From the interview, it is clear that Olly is operating at pre- action level because there was no understanding of the question requirements. He just presented what he remembered which was not even correct. A misconception was also exhibited when he stated that $\mathrm{b}$ is the gradient of the quadratic function. These findings were similar to what Ellis and Grinstead (2008) found from researches carried out, where many students related the coefficients $a$, $\mathrm{b}, \mathrm{c}$ to the slope of the quadratic graph, which is incorrect. On the effect of varying b, during his study, Ibeawuchi (2010) proposed the idea of drawing a quadratic graph with $a$ and $c$ remaining constant while $b$ changes. It was however noted that no one of the respondents tried the problem in a similar way.

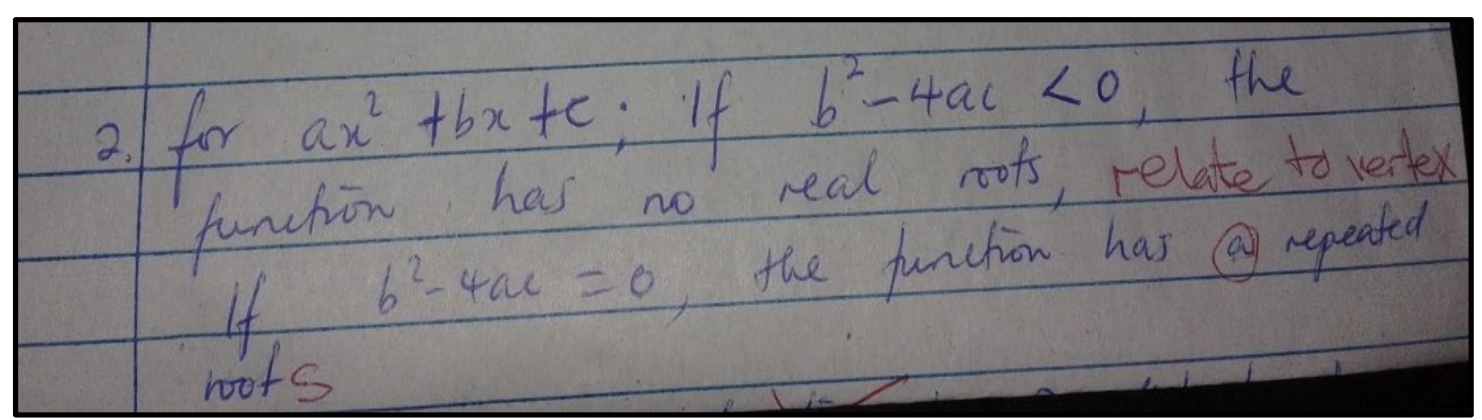

Figure 5. Student y's written response on the work on parabola 
Instead of explaining the effects of varying the constants $a, b, c$ on the vertex, the student talked of roots instead. During the follow up interview, the student indicated that this was all he remembered on the constants $a, b, c$. The student is operating at the action level on this item where he memorized some formulae and tried to use them, but in the wrong place. The question was not conceptualized.

\section{Students Understanding of Graphical Representation}

Question 3 aimed at exploring the preservice teachers understanding of the curve sketching and its applications. The question addresses the object understanding of the quadratic function according to the genetic decomposition. Question 3 is represented in Table 5 and the frequencies of scores are shown in Table 6.

Table 5. Question 3

3) Given the following function: $f(x)=x^{2}+4 x+4$,

a) draw the graph of the function.

b) find the vertex is (---, ---) and is it minimum or maximum?

c) write the quadratic function in vertex form.

d) how would you explain the vertex concept in relation to axis of symmetry to a ZJC class?

Table 6. Frequencies of scores for item 3

\begin{tabular}{ccccc}
\hline Category & $\mathbf{1}$ & $\mathbf{2}$ & $\mathbf{3}$ & $\mathbf{4}$ \\
\hline Indicator & Sketch the graph & $\begin{array}{c}\text { Present function in } \\
\text { vertex form }\end{array}$ & $\begin{array}{c}\text { Explain vertex in terms of } \\
\text { symmetry }\end{array}$ & concavity \\
\hline Number of responses & 24 & 6 & 6 & 12 \\
\hline
\end{tabular}

Question 3a required the learner to draw the parabola and say if it is concave up or concave down. Most students got confused by the terms resulting in half of the students getting the answers correct and the other half getting wrong answers. From the follow up interviews it was noted that the students were familiar with the terms: concave and convex not concave up or down. The half which got it wrong did not construct the action conception of the concept. They are operating at pre-function level. The other half has reached the action level of APOS.

\section{Sketching the Parabola}

All the respondents managed to draw the graph of the parabola; however, two students created tables of values in order to draw the graph. Their conception of graphing is rooted on table of values. Almost all the student teachers exhibited the process level except for the two who could do nothing without generated values.

\section{Vertex Form of a Quadratic Function}

From the twenty-four participants, only six had an idea of the meaning of vertex form. Majority of the respondents confused it with the factorized form. Others had no idea of finding the vertex form. Some used the method of completing the square to express the function in vertex form, while others got the answer correct but did not show the working. When dealing with the axis of symmetry, the participants viewed it in two ways:

- As a line that bisects the vertex or the whole graph as a whole,

- As a number derived from the formula $-\frac{b}{2 a}$.

As for the vertex, the participants considered it to be the highest or the lowest coordinate pair $(x, y)$, depending on which direction the parabola was orientated. Below are more students' test extracts and the interview excerpts:

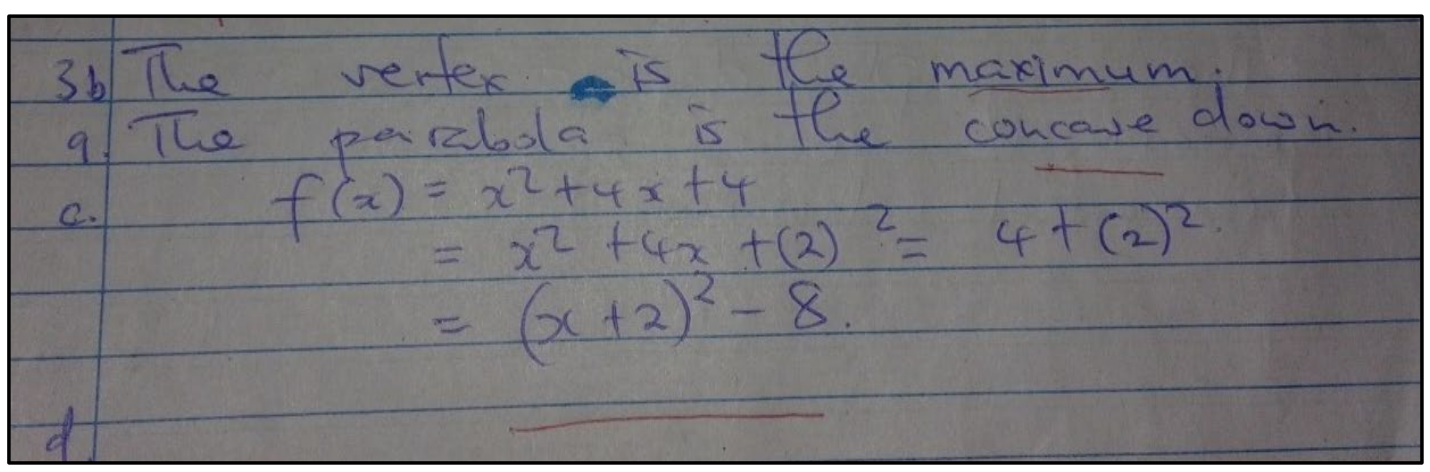

Figure 6. Ten's written response on the understanding of the vertex concept 
Ten did not draw the graph so it became difficult for him to tell that the vertex is a minimum. Most students do not enjoy graph work, which a weakness for most Mathematics student teachers. This weakness was also highlighted by lecturers in the questionnaires they answered. This is also supported by Ellis and Grinstead (2008) who said that students have problems in linking algebraic statements with graphical representations. He got a wrong answer on that second part because his first part was incorrect. Ten did not even state the coordinates of the vertex. The stages for completing the square method were incorrectly done. He failed to attempt the last part of the item. According to (Dubinsky and Harel, 1992), Ten is operating at Pre-function level. This level is not contained in the preliminary genetic decomposition, hence the need to come up with a modified genetic decomposition as substantiated by Ndlovu and Brijlall (2015). Ndlovu and Brijlall propounded that if differences in student performance cannot be explained by the genetic decomposition, then that would be implying that the genetic decomposition needs revision. An interview was done to get some explanations on Ten's written work.

\section{Ten's Interview (Excerpt 4)}

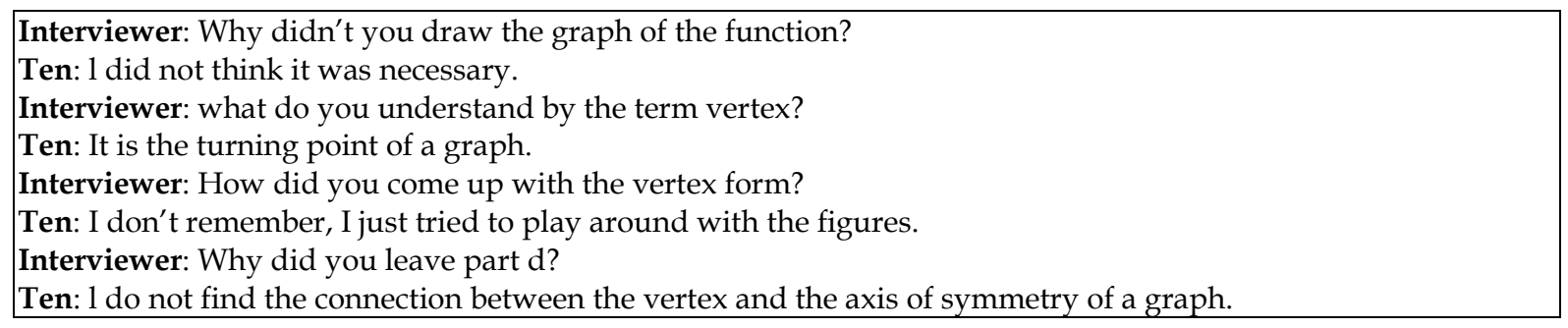

The interview excerpt indicates that there are no rules or algorithms used when he dealt with the question. The preliminary genetic decomposition in Figure 2 could not explain Ten's level. Ten could be operating at a level below the action level which Dubinsky \& Harel (1992) named pre- function level as stated in their findings. According to Ball \& Bass (2000), Ten may have difficulties in teaching the concept which is difficult for him to understand. This situation then calls for revision of the preliminary genetic decomposition in order to come up with a modified one. This is in agreement with what Ndhlovu and Brijlall (2015) propounded in their research on matrix algebra.

\section{Students' Understanding of Quadratic Word Equations}

Question 4 is represented in Table 7. The question addresses the object understanding of the concept of quadratic equations. The frequencies of scores are represented in Table 8.

Table 7. Question 4

The height $h$, in metres of an object above the ground is given by $h=16 t^{2}-64 t+19$, where $t$ is time in seconds and it is given that $t \geq 0.5$. Find the time it takes the object to strike the ground and find the minimum/maximum height of the object.

\begin{tabular}{|c|c|c|c|c|c|c|c|}
\hline Category & 1 & 2 & 3 & 4 & 5 & 6 & 7 \\
\hline Indicator & $\begin{array}{l}\text { No } \\
\text { attempt } \\
\text { made. }\end{array}$ & $\begin{array}{c}\text { Attempted and } \\
\text { got a wrong } \\
\text { answer. }\end{array}$ & $\begin{array}{l}\text { Used } \\
\text { quadratic } \\
\text { formula } \\
\text { wrongly. }\end{array}$ & $\begin{array}{l}\text { Used the } \\
\text { quadratic } \\
\text { formula and } \\
\text { got only the } \\
\text { first part } \\
\text { correct. }\end{array}$ & $\begin{array}{l}\text { Substituted a } \\
\text { wrong t to } \\
\text { find the } \\
\text { minimum } \\
\text { height of the } \\
\text { object. }\end{array}$ & $\begin{array}{l}\text { Answered } \\
\text { the whole } \\
\text { question } \\
\text { correctly. }\end{array}$ & $\begin{array}{c}\text { Answered the } \\
\text { whole question } \\
\text { but was not sure } \\
\text { of their answers } \\
\text { to the second } \\
\text { part. }\end{array}$ \\
\hline Number of responses & 1 & 1 & 1 & 10 & 8 & 1 & 2 \\
\hline
\end{tabular}

The question required the respondents to calculate the time taken by the object to strike the ground and the minimum height of the object. One student did not even attempt to answer the question. A follow up interview on this student revealed that he had no idea of how to go about it. Another student used an incorrect quadratic formula in the process of trying to answer the first part of the item. The student used 2ac instead of $2 \mathrm{a}$ as the denominator of the quadratic formula. According to APOS, these three students did not even fit in the action level but below the action level. The students are said to be operating at pre-function level as propounded by Dubinsky and Harel (1992). Ten students were operating at action level since they were able to use the quadratic formula correctly to find the time taken by the object to strike the object, however, they managed to answer the first part only. On the second part, eight students failed to find the $x$ value of the turning point of the graph but simply substituted the value they got in part (a) which was not correct. Only one respondent got the whole question right. He clearly understood what was going on even without constructing the graph. The student teacher performed a new Mathematical operation of the quadratic concepts. According to APOS theory, this student is operating at the process level. A student operating at this stage can represent the solution using different forms. They can also 
explain and justify use of a chosen method used. Reviewed literature indicates that this student has greater chances of adopting methodologies which foster conceptual understanding of concepts as propounded by Ball and Bass (2000). However, two students seemed to be operating at the process level. They correctly used the formula $\frac{-b}{2 a}$ to find the $x$ value of the vertex point but had a weakness of failing to complete their calculation of the $y$ value because they were no longer comfortable with a negative y value they got.

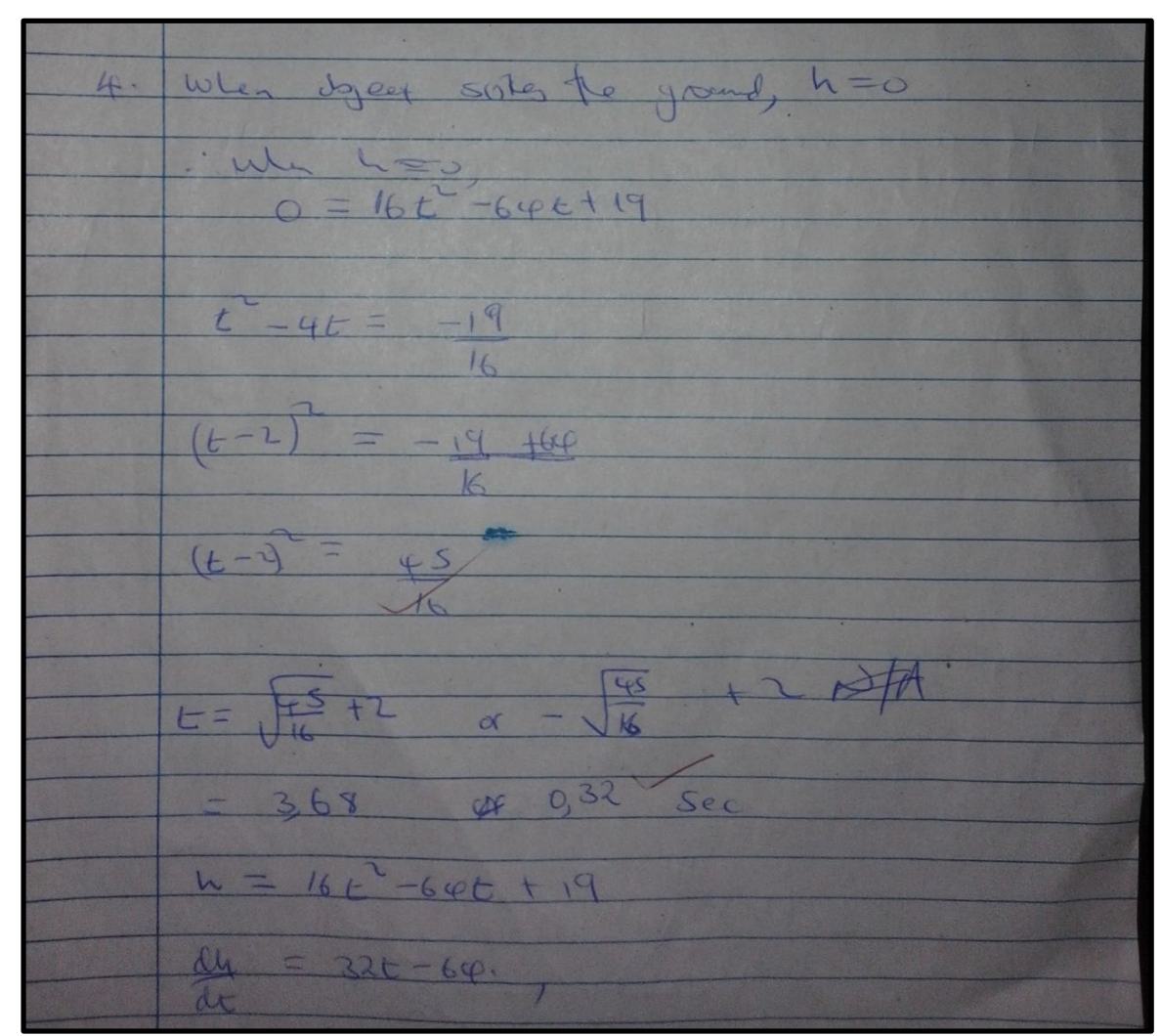

Figure 7. Tam's written response on understanding of quadratic word equations

Tam's work proves that he can actually work with problems in different forms, and has encapsulated the processes into a cognitive object (Dubinsky \& Mcdonald, 2001). From these findings, the preliminary genetic decomposition fits well with the exhibited mental constructions.

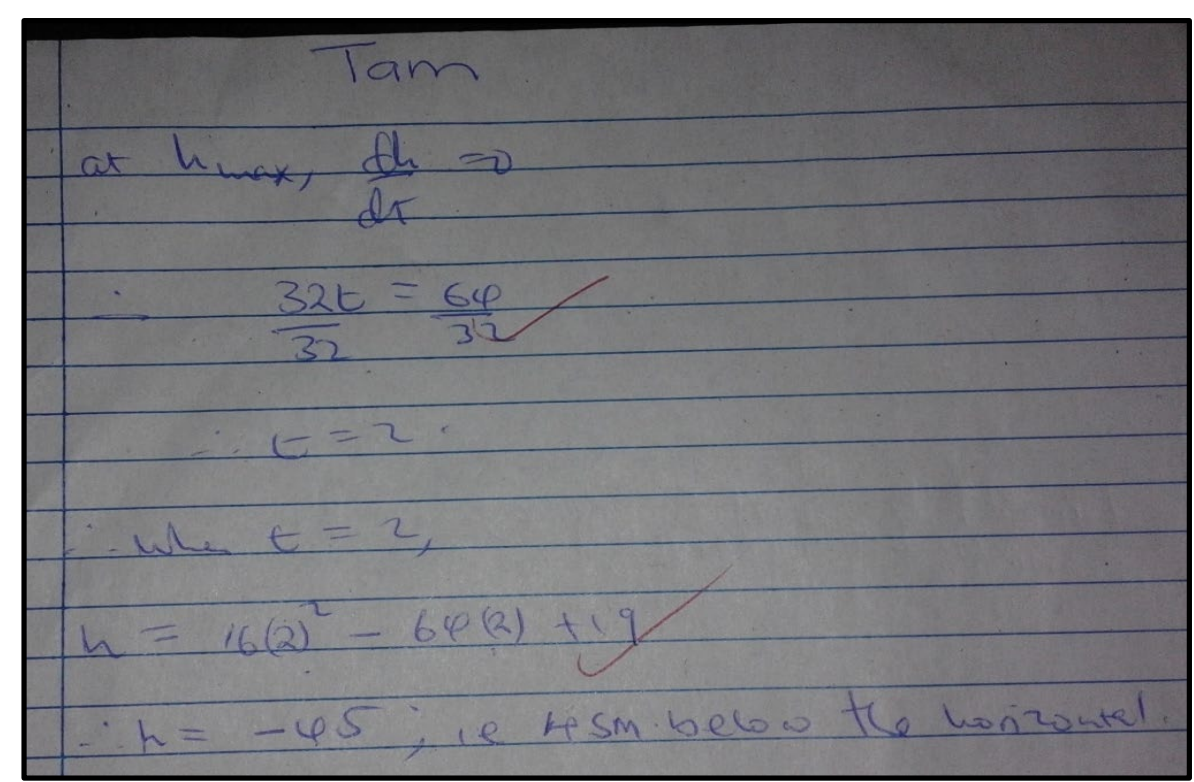

Figure 8. Tam's written response on understanding of quadratic word equations 
Tam exhibited conceptual understanding of the quadratic function concept. No weaknesses shown in his work. This implies that if he is to teach this concept, he would use methodologies which promote conceptual understanding since there is a linkage between one's content knowledge and pedagogical knowledge as substantiated by (Ball \& Bass, 2000; Hill \& Ball, 2004). The follow up interview outcome also supports the analysis above.

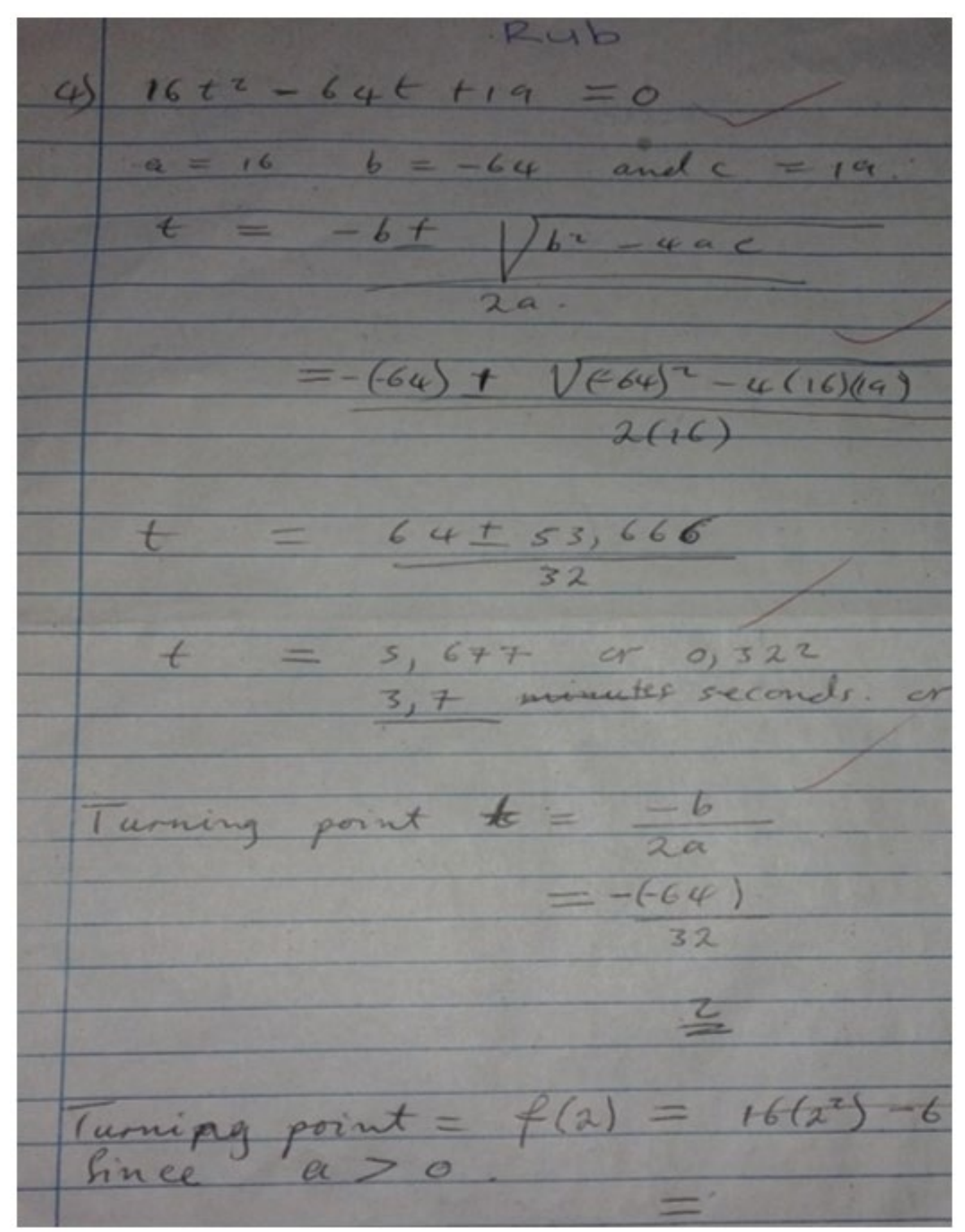

Figure 9. Rub's written response on understanding of quadratic word equations

The follow up interview results with Rub revealed that he clearly understood in his mind the requirements of the question but he was not sure whether he was still in the right tract since he was about to get a negative answer. This showed that he had interiorized the actions into processes, so he was operating at process level where the actions actually occur in the mind (Dubinsky \& Mcdonald, 2001). The only weakness which Rub showed was lack of confidence in what she was doing. This may even affect her selection of teaching methodology as propounded by (Borko et al., 1992; Grossman, Wilson, \& Shulman, 1989). The preliminary genetic decomposition managed to link well with these findings. 


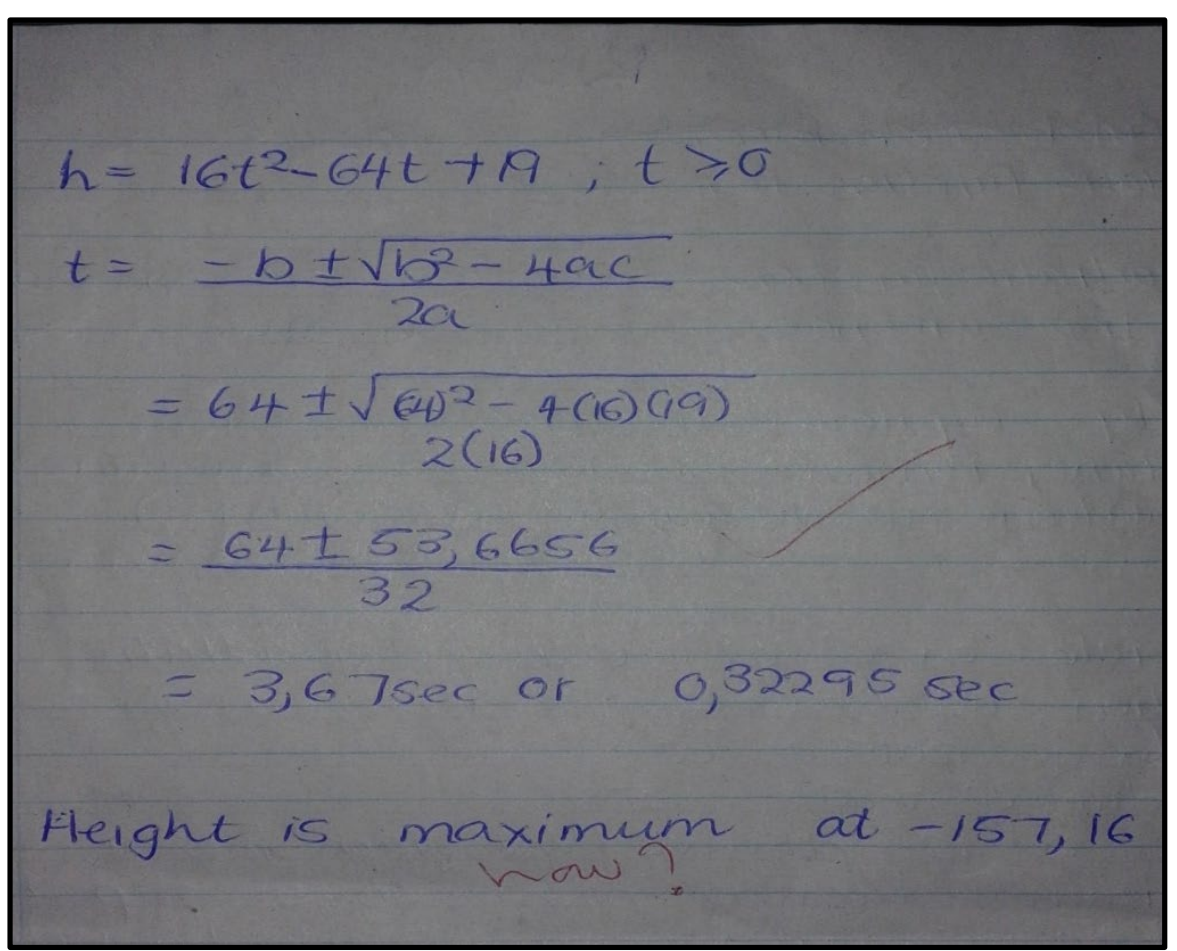

Figure 10. Bri's written response on understanding of quadratic word equations

There is clear evidence that Bri is operating at the action level, where the quadratic formula was correctly used to get the values of $t$. The second part of the question was difficult for him that he ended up putting down the answer without showing working. However, interview confirmed that this answer $(-157,16)$ was obtained by substituting 3, 67 (obtained in part a) into the original quadratic function, which is a misconception. This is similar to what Leinhardt et al. (1990) found out. Misconceptions are identified as incorrect features of student's knowledge that are repeatable but not simply an error.

\section{DISCUSSION AND CONCLUSION}

This paper has provided answers to the research questions. Results revealed that students operate at different levels of APOS on certain concepts. Generally, most student teachers were at the action level. Very few interiorised the action level to the processes stage. Two student teachers managed to go through encapsulations of processes to form object. No one reached the schema stage of APOS on the quadratic function concept. It was observed that these preservice teachers had a lot of misconceptions and errors. Some incorrectly took it as the gradient of the quadratic function, which is a misconception from the linear functions. This is in agreement with what Zaslavsky (1997) and Ellis and Grinstead (2008) found out in their studies that in most cases students tend to treat liner and quadratic functions in the same manner. In this study, most students thought that the value of $c$ in the quadratic function $y=a x^{2}+b x+c$ and linear function $y=a x+c$ is gradient. This is actually a misconception which is a sign of inadequate mental constructions leading to lack of conceptual understanding of the gradient concept.

Another weakness was on parabolic transformations (question 2). Students' weakness was that they did not really understand the values of the coefficients on the quadratic formula. Moreover, they did not even think of drawing the graphs while varying the values of one constant at a time in order to study the pattern. On the quadratic word problem, a lot of students failed to link and transform the number story to the quadratic functions. This exhibited an APOS level which is far below object level. The moment they saw the quadratic equation, they only thought of solving it without clear understanding of the question. However, most respondents managed to solve it correctly showing that they were able to carry the actions correctly implying that they fall in the action level of APOS.

\section{Implication of the Study}

The fact that the study revealed that preservice teachers operate at different levels of understanding on concepts, it therefore calls for the need to cater for these human differences by allocating more time to more challenging concepts which are taught in schools. It is also crucial for preservice teachers to acknowledge that as pupils come into classrooms, they have different levels of grasping concepts. Consequently, it is recommended that first year 
students be given time for thorough exposure on quadratic function concept which they would teach at 'O' Level. This promotes a good understanding of the concept. Most of them have no conceptual understanding of parabolas, vertices, quadratic word problems and quadratic transformations. Some mental constructions may be pushed to a higher level as they interact more with some content. Action level maybe interiorized into process level and the process level may be encapsulated into an object level. They may result in the teachers having problems with selecting suitable methodologies which fosters conceptual understanding of concepts. Teachers are therefore recommended to design instructional methodologies that help students to improve their level of understanding of quadratic function concept. Since the research was based on APOS Theory which was fathered by Dubinsky (1984), it is imperative for educators to join research organizations so that they keep abreast with current information.

The extent to which the preliminary genetic decomposition explained the pre-service teachers' responses.

It was noted from the discussion that some of the mental construction link with the preliminary genetic decomposition, but some of the students' responses could not be explained or accommodated by the preliminary genetic decomposition. Some responses were not clearly stated, hence the need for follow up interviews in order to probe and understand their mental constructions based on the written responses. It was noted that the preliminary genetic decomposition needed a refinement in order to accommodate these gaps. This lead to a modified genetic decomposition presented below. For example for the conceptualization of parabolas, the model did not include the schema of the method to use when finding vertex. Thus it was seen that the method of completing the square was seen as action. The ability to construct a graph without showing the step by step procedures was seen at the process stage and the individual must be able to explain how to draw a parabola without any set of values, which is explaining how the maximum or minimum values are arrived at. Thirdly the ability to transform any vertex to form graphs in which actions and processes can be applied is at the object stage.

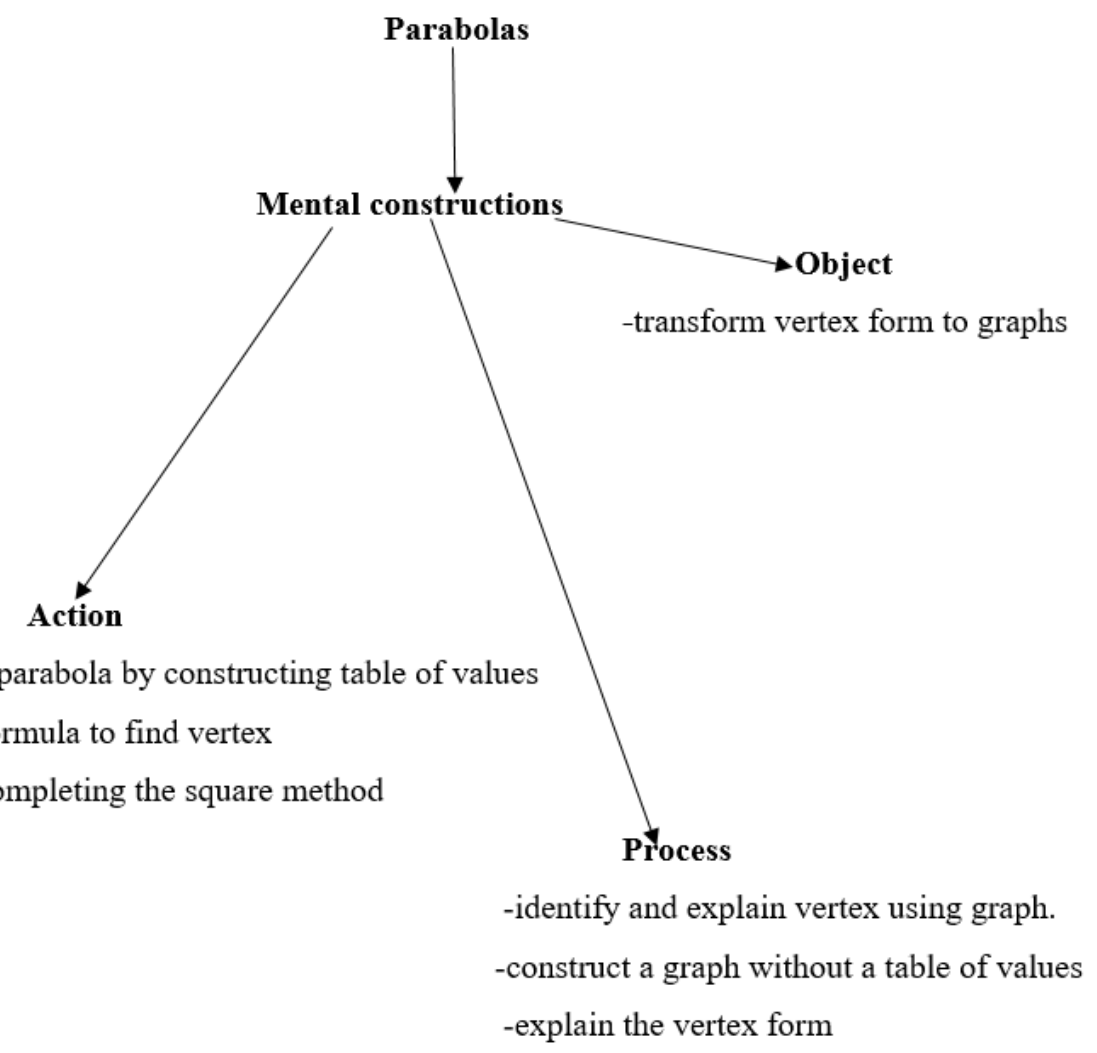

Figure 11. A modified genetic decomposition of the concept; parabola

Also for the conceptualization of word problems, to be able to use the correct quadratic formula was seen as action and this was not included in the preliminary genetic decomposition. However to be able to describe and make connection between the word problem involving quadratic equation and understanding the meaning was placed at the process stage. Thirdly to recognize and transform word problems to graphs is applied at the object stage. 


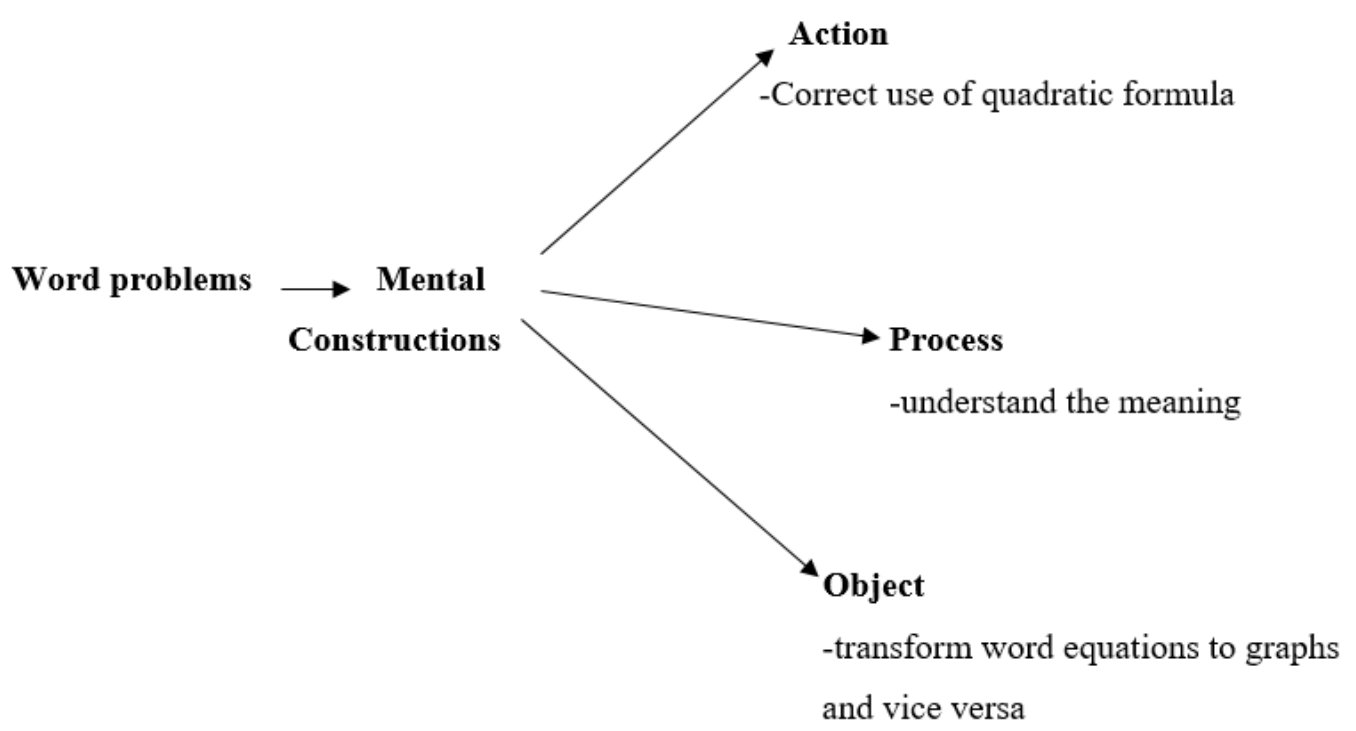

Figure 12. A modified genetic decomposition of the concept; word problems

On the quadratic word problem, a lot of students failed to link and transform the number story to the quadratic functions. This exhibited an APOS level which is far below object level. The moment they saw the quadratic equation, they only thought of solving it without clear understanding of the question. However, most respondents managed to solve it correctly showing that they were able to carry the actions correctly implying that they fall in the action level of APOS.

\section{Implications for the Study}

The fact that the study revealed that pre-service teachers operate at different levels of understanding on concepts, it therefore calls for the need to cater for these human differences by allocating more time to more challenging concepts which are taught in schools. It is also crucial for pre-service teachers to acknowledge that as pupils come into classrooms, they have different levels of grasping concepts. Consequently, it is recommended that first year students be given time for thorough exposure on quadratic function concept which they would teach at ' $\mathrm{O}$ ' Level. This promotes a good understanding of the concept. Most of them have no conceptual understanding of parabolas, vertices, quadratic word problems and quadratic transformations.

Some mental constructions may be pushed to a higher level as they interact more with some content. This therefore means that since these teachers are operating at different conceptual levels of understanding and most them some did not understand these concepts clearly, thus to some extend they pass on this lack of knowledge to the pupils leading to some schools performing badly at the end of the year.

\section{Suggestions for Future Studies}

It was found from the study that learners make a lot of misconceptions as they learn concepts. It is therefore imperative for educators to identify these misconceptions and find ways of dealing with them. Current technologies like graphical calculators, computer software can be effectively used in classrooms to reduce misconceptions held by students. Educators share the above important ideas at organizations like Southern African Association Research of Mathematics, Science, Technology and Engineering (SAARMSTE), which may include misconceptions held by students on specific concepts and how they can be eradicated.

\section{ACKNOWLEDGEMENTS}

The author thanks the anonymous referees for their constructive comments and inputs.

\section{REFERENCES}

Akpan, A. A. (1987). Correlation of mathematical problem-solving ability among secondary school students in the Cross River State of Nigeria. Thesis, University of Ibadan.

Asiala, M., Brown, A., DeVries, D. J., Dubinsky, E., Matthews, D., \& Thomas, K. (1996). A framework for Research and Development in Undergraduate Mathematics Education, 2, 1-32. https:/ / doi.org/10.1090/cbmath/006/01 
Ball, D. L., \& Bass, H. (2000). Interweaving content and pedagogy in teaching and learning to teach: Knowing and using mathematics. In J. Boaler (Ed.), Multiple perspectives on the teaching and learning of mathematics, (pp. 83104). Westport, CT: Ablex.

Borgen, K. L., \& Manu, S. S. (2002). What do students really understand? Journal of Mathematical Behaviour, 21(2), 151-165. https:/ / doi.org/10.1016/S0732-3123(02)00115-3

Borko, H., Eisenhart, M., Brown, C. A., Underhill, R. G., Jones, D., \& Agard, P. C. (1992). Learning to teach hard mathematics: do novice teachers and their instructors give up too easily? Journal for Research in Mathematics Education, 23(3), 194-222. https:// doi.org/10.2307/749118

Bourdieu, P., Chamboredon, J. C., \& Passeron, J. C. (2000). The Craft of Sociology: Epistemological Preliminaries. New York: Walter de Grayter.

Breidenbach, D., Dubinsky, E., Hawks, J., \& Nichols, D. (1992). Development of the process of conception of function. Educational studies in Mathematics, 23, 247-285. https:/ / doi.org/10.1007/BF02309532

Burke, M., Erickson, D., Lott, J. W., \& Obert, M. (2001). Navigating through Algebra in Grades 9-12. Reston, VA: National Council of Teachers of Mathematics.

Burns, S. N., \& Grove, S. K. (2003). Understanding nursing research (3rd ed.). Philadelphia: Saunders. Cape Town: AMESA.

Chazan, N. (1992). Africa's democratic challenge. World Policy Journal, 9(2), 279-307.

Cooney, T. J., \& Wilson, M. R. (1993). Teachers' thinking about fractions; Historical and Research perspectives. In T. Romberg, E. Fennema, \& T. Carpenter (Eds.), Integrating research on the graphical representation of functions, (pp. 131-151). Hillsdale, NJ: Lawrence Erlbaum Associates.

Donevska-Todorova, A. (2016, March). Procedural and Conceptual Understanding in Undergraduate Linear Algebra. In First conference of International Network for Didactic Research in University Mathematics.

Dubinsky, E. (1991). Reflective Abstraction. In D. O. Tall (Ed), Advanced Mathematical.

Dubinsky, E., \& Harel, G. (1992). The concept of function, aspects of epistemology \& pedagogy. MAA Notes, 25, 85106.

Dubinsky, E., \& Mcdonald, M. A. (2001). APOS: A Constructivist Theory of Learning in Undergraduate Mathematics Education Research. In: D. Holton, M. Artigue, U. Kirchgräber, J. Hillel, M. Niss, A. Schoenfeld (Eds.), The Teaching and Learning of Mathematics at University Level. New ICMI Study Series, vol 7. Springer, Dordrecht.

Ellis, A. B., \& Grinstead, P. (2008). Hidden lessons: How a focus on slope-like properties of quadratic functions encouraged unexpected generalizations. The Journal of Mathematical Behavior, 27(4), 277-296. https://doi.org/10.1016/j.jmathb.2008.11.002

Fajemidagba, M. O. (1986). Mathematical word problem solving: An analysis of errors committed by students. The Nigerian Journal of Guidance and Counseling, 2(i), 23-30.

Grossman, P. L., Wilson, S. M., \& Shulman, L. S. (1989). Teachers of substance: Subject matter knowledge for teaching. Profesorado, Revista de Currículum y Formación del Profesorado, 9(2), 1-25.

Hartley, J. (2004). Case study research. In C. Cassell \& G. Symon (Eds.), Essential guide to qualitative methods in organizational research (pp. 323-333). London: Sage. https:// doi.org/10.4135/9781446280119.n26

Hill, H. C., \& Ball, D. L. (2004). Learning mathematics for teaching: Results from California's mathematics professional development institutes. Journal for research in mathematics education, 330-351. https:/ / doi.org/10.2307/30034819

Ibeawuchi, E. O. (2010). The role of pedagogical content knowledge in the learning of quadratic functions. Pretoria.

Jojo, Z. M. M. (2011). An APOS exploration of the conceptual understanding of the chain rule in calculus b first year engineering students (Unpublished Doctoral Thesis), University of KwaZulu-Natal, South Africa.

Kotsopoulos, D. (2007). Unravelling student challenges with quadratics. Australian Mathematics Teacher, 63(2), 1924.

Leinhardt, G., Zaslavsky, O., \& Stein, M. K. (1990). Functions, graphs, and graphing: Tasks, learning and teaching. Review of Educational Research, 60, 1-64. https:/ / doi.org/10.3102/00346543060001001

Maharaj, A. (2013). An APOS analysis of natural science students' understanding of mathematics at University level: An ICMI study. South African Journal of Education, 33(1). https:/ / doi.org/10.15700/saje.v33n1a458

Ndlovu, D., \& Brijlall, D. (2015). Pre-service Teachers mental constructions of concepts in Matrix Algebra. African Journal of Research in Mathematics Science and Technology Education, 19(2), 1-16. https:/ / doi.org/10.1080/10288457.2015.1028717 
Owens, J. E. (1992). Families of parabola. The Mathematics Teacher, 85(6), 477-479.

Parameswaran, R. (2007). On Understanding the Notion of Limits and Infinitesimal Quantities, International Journal of Science and mathematics Education, 5(2), 193-216. https:/ / doi.org/10.1007/s10763-006-9050-y

Parent, J. S. S. (2015). Students' understanding of quadratic functions: Learning from students' voices. Doctor of Education. University of Vermont.

Romberg, T. A., \& Fredric W. T. (1992). Mathematics Curriculum Engineering: Some Suggestions from Cognitive Science, The Monitoring of School mathematics: Background Papers, (2).

Shulman, L. (1986). Knowledge and teaching: Foundations of the new reform. Harvard educational review, 57(1), 123. https:/ / doi.org/10.17763/haer.57.1.j463w79r56455411

Siyepu, S. W. (2013). Students' interpretations in learning derivatives in a university Thinking, (pp. 95-123), Dordrecht: Kluwer Academic Publishers.

Zaslavsky, O. (1997). Conceptual obstacles in the learning of quadratic functions. Focus on Learning Problems in Mathematics, 19(1), 20-44.

\section{http://www.ejmste.com}

